\title{
Regressão à dependência e o brincar - novos sentidos da transferência em Winnicott
}

\section{Regression to dependency and play - new meanings of transference in Winnicott}

\author{
Tânia Corrallo Hammoud
}

\begin{abstract}
Resumo: o texto reflete sobre o significado da transferência para Winnicott. Apoiado num caso, o texto busca articular esse conceito aos de regressão à dependência, brincar e presença viva do analista como suportes da análise.
\end{abstract}

Palavras-chave: regressão à dependência, brincar, espaço potencial, presença viva do analista

Abstract: the text reflects on the meaning of the transference to Winnicott. Supported in one case, the text seeks to articulate this concept with those of regression to dependency, play and the analyst's living presence as support for analysis.

Keywords: regression to dependency, play, potential space, living presence of the analyst

Ao tratar da transferência, Winnicott formula algumas novidades essenciais: o sentido dado à regressão à dependência, ao brincar e à presença viva do analista no setting. Para ele, no espaço da análise, aquilo que de fundamental se dá não é a transferência de representações pretéritas, deslocadas para a figura do analista e que deverão ser decifradas e interpretadas. Trata-se de algo que tem a ver com experiências reais entre duas pessoas, uma concedendo à outra um espaço no qual possa conquistar as tarefas básicas do viver: ser a partir de si mesma e relacionar-se de forma contributiva com o mundo. Para que esse espaço propicie tais conquistas, é necessário que seja um espaço de dependência, onde a confiança é construída; um espaço potencial, livre da intrusão do outro, e onde, ainda assim, exista a presença viva e interessada do analista.

A proposição essencial é a de que, no encontro psicanalítico, não importa diante de qual momento do amadurecimento se esteja, o que conta é a veracidade desse encontro, a qual é determinada pela qualidade da presença viva do analista (Winnicott, 1962, p. 152). Essa presença tem como atributos essenciais a capacidade para se colocar empaticamente no lugar do outro, permitindo que este faça o mesmo consigo, bem como a capacidade para brincar. Apoiado no primeiro atributo, ou seja, a 
capacidade para as identificações cruzadas (Winnicott, 1968, p. 186), o analista identifica o sofrimento do paciente e propicia uma regressão não a seus pontos de fixação no desenvolvimento libidinal, mas ao momento da linha do amadurecimento no qual uma falha se deu e algo deixou de ser vivido, deixou de ser integrado. Nesse espaço, analista e paciente brincam e criam juntos espaços para que as integrações necessárias aconteçam, para que o amadurecimento seja retomado. Assim, no inter jogo dessas experiências, que envolvem regredir, brincar, sonhar, em um ir e vir de identificações que se cruzam, a análise vai acontecendo. A transferência é entendida, portanto, como uma regressão à dependência de um ambiente suficientemente bom, capaz de empatizar de forma viva com o paciente e também capaz de brincar, propiciando a retomada do amadurecimento.

Para Winnicott,

A importância do brincar é sempre a precariedade do inter jogo entre a realidade psíquica pessoal e a experiência de controle de objetos reais. É a precariedade da própria magia, magia que se origina na intimidade, num relacionamento que está sendo descoberto como digno de confiança. Para ser digno de confiança, o relacionamento é necessariamente motivado pelo amor da mãe, não por formações reativas (Winnicott, 1968, p. 71).

O processo de análise, portanto, acontece, em alguma medida, através de uma experiência mágica, em um espaço/tempo de intimidade e confiança, real e verdadeiro, não de formações reativas, como acontece também com o brincar. É nesse contato, assim entendido, que transferência e contratransferência ganham significados novos para Winnicott, revolucionando a forma de entender e de fazer psicanálise, como já é sabido. Uma tarefa difícil, porém, necessária. Isso porque aí reside mais um dos paradoxos winnicottianos: ao mesmo tempo em que se faz necessário ali se estar de forma viva e presente, é também necessário dar ao paciente a primazia da experiência, sem invadir seu movimento. Afinal, o piquenique é do paciente, como o autor sugere através dessa imagem que brinca com o sentido do fazer analítico (Winnicott, 1965, p. 247).

Sobre isso, compartilho agora um caso que pode ser útil na compreensão dos aspectos mencionados até então. Tita, como será aqui chamada a paciente, desde o início, despertou em mim um profundo interesse pelas coisas que trazia e pela forma muito pessoal e poética que tinha de formulá-las. Ela dizia coisas como: "É difícil habitar a realidade, mas é possível frequentá-la". Esse interesse, quase inevitável, 
somado a uma possibilidade de conviver em um tempo muito pessoal, marcado por muitas idas e vindas, teceu o ambiente de sustentação através do qual ela pôde viver a experiência do resgate de si mesma.

Dois fatos importantes marcam essa análise. Primeiro: ela tem se realizado em um espaço/tempo que é o da paciente, habitado por ela através de algumas modalidades de afastamento. Ela precisa aproximar-se e afastar-se de mim, quer seja dentro de uma mesma sessão, por silêncios, recusas daquilo que lhe digo, quer seja entre as sessões, faltando e retomando. Habitar esse espaço/tempo à sua forma e ritmo tem sido essencial. Segundo: a análise de Tita me coloca sempre como participante ativa das formulações que a paciente tece nas sessões. Sinto muito interesse por tudo o que ela traz e formula; a própria paciente espera e demanda que eu participe de suas formulações. Assim, Tita e eu vamos brincando de encontrar sentidos para suas experiências. É necessário que esses sentidos sejam encontrados por ela mesma, mas através de uma experiência na qual eu sirva de espelho, no sentido winnicottiano do conceito; espelho através do qual ela se encontra (Winnicott, 1967, p. 161; Winnicott, 1968, p. 164). É o interesse genuíno com o qual a ouço que funciona como suporte para suas experiências de integração, as quais vão acontecendo gradativamente.

Tita, que começou sua análise aos 32 anos, é artista plástica e arte educadora, casada, sem filhos. Sua queixa, no início do tratamento, era de dificuldades com a profissão e com o casamento; "com a vida", como ela mesma dizia. Aos dois anos de idade, viveu uma quebra na relação com a mãe, até então muito próxima, em função do nascimento de uma irmã doente. A paciente estruturou, então, uma defesa que oscilava entre um certo isolamento, marcado por muitas "idas para o mundo das ideias", segundo sua própria formulação, e uma dependência das pessoas que a aprisionava a elas.

Em um momento mais recente da análise, descreveu uma experiência de quando contava com sete ou oito anos. Costumava brincar com um espelho grande, colocando-o debaixo do queixo em frente ao peito e movendo-se pela casa, lugar no qual não se sentia à vontade. Conforme andava, orientava-se pelas imagens do teto que eram refletidas no espelho. Disse que, embora batesse nas coisas da casa, sentia-se mais confortável movimentando-se em um espaço, por assim dizer, criado por ela. Comentou que quando convidava outras crianças para participar da brincadeira, elas nada entendiam. 
Mais tarde, já adolescente, viveu experiências da seguinte ordem: via alguma coisa, uma casa, por exemplo, que lhe despertava um prazer estético. A casa, então, entrava dentro dela, tomava-a, e ela ali ficava um bom tempo. Não havia perda do sentido de realidade, mas uma espécie de distanciamento necessário para que a vivência daquela experiência específica pudesse se dar, tal como pude entender a partir dos relatos que fazia. Isso podia acontecer também com uma conversa que, da mesma maneira, acabava entrando dentro dela. Conversar com uma amiga podia tomá-la por dias, sem que conseguisse voltar para suas próprias questões. Nas palavras dela, era como se estabelecesse uma relação com as coisas na qual "entrava", uma espécie de dependência, e não conseguisse se separar daquilo por um tempo. Não era ruim, disse, mas podia tomar dias e dias até que conseguisse voltar completamente a si mesma. Com frequência, no campo da arte, desistia de expor seus trabalhos por medo de não ser bem compreendida e ficar preconceituosamente atada à crítica. Já com o trabalho na área de educação, não conseguia adaptar-se às exigências da instituição, entendendo-as como ingerência em seu fazer, desistindo e não conseguindo, portanto, sobreviver de seu próprio trabalho. Com o marido, mantinha uma relação de dependência financeira e afetiva. Viviam uma relação quase simbiótica, diante da qual ela se sentia oprimida, sufocada, sem conseguir ter seu próprio espaço e forma respeitados. Conseguir ser ela mesma demandava uma presença firma e forte que não se sentia capaz de assumir. O medo da perda do vínculo de um lado e o da perda de sua identidade de outro eram apavorantes.

Em uma tentativa recente de descrever sua necessidade, ela disse:

Eu preciso [no contato com as pessoas] tocar e ser tocada e produzir uma terceira coisa na qual eu e a outra pessoa possamos nos reconhecer. Eu olho e pesco alguma coisa daquilo que vejo, que pode ser qualquer coisa, mas isso que eu pesco é como eu vejo; aí faço alguma coisa com aquilo: escrevo um texto, faço as crianças perceberem que a brincadeira delas é uma performance, coloco isso numa exposição, ou qualquer outra coisa, mas é isso que importa, que ao pescar e fazer algo com isso, que é meu e devolver ao outro, o outro se deixe tocar e também se veja naquilo que foi criado.

Essa experiência de criação de sentidos para o seu viver, inevitavelmente cativante, ajuda-a a construir a si mesma, determinando uma análise na qual o tema trazido pela paciente pode ser colocado na pergunta: vamos brincar de criar significados para minha existência? Entro um pouco em seu mundo e você entra no meu; a gente experimenta onde isso vai dar para que eu possa ser eu mesma. A 
demanda por uma escuta interessada, bem como a demanda de permissão de seu ir e vir criaram um espaço no qual as interpretações praticamente não tiveram importância, isso porque uma experiência viva estava em curso, dispensando o entendimento simbólico. O espaço do brincar foi o suporte para a mudança conquistada. Parafraseando Winnicott, nós nos contentávamos simplesmente em tomar parte de um exercício de fertilização cruzada, aguardando o momento de saber que ser híbrido poderia resultar daquela mistura (Winnicott, 1968, p. 51).

Esse era o pano de fundo sobre o qual a realidade dessa análise em particular se deu. Para que a experiência pudesse ser vivenciada dessa maneira, foi preciso passar por muitos momentos difíceis de regressão a momentos de dependência, os quais envolviam a minha sobrevivência, dado que Tita precisava integrar, sobretudo, sua agressividade. Um exemplo disso foi quando, diante da recusa em aceitar minha participação em suas ricas formulações, a paciente adivinhou, muitas vezes, minha decepção por ser colocada do lado de fora da brincadeira. Por vezes, eu parecia murchar, logo depois de ter me sentido "com a bola toda". E, no entanto, era exatamente dessa dualidade que a paciente precisava: que eu ficasse tanto de fora do momento quanto que mantivesse o interesse em seus relatos de experiência quando de seu "retorno". Diante de suas ausências, o medo de que não retornasse comparecia. Viver autenticamente esses momentos, por vezes a eles sobrevivendo e por outras não, era também o motor da análise.

Para Tita, a busca essencial era a de ser ela mesma em contato com o outro. Perder a atenção da mãe que passou a cuidar da irmã doente representou para ela uma dupla quebra em sua continuidade de ser: já não contava com o suporte que lhe permitia ser ela mesma na presença de alguém que tinha um profundo interesse por ela e, fato de importância decisiva, temia sua agressividade, como se tivesse estragado tudo ao seu redor, mãe, irmã e mesmo o casamento dos pais, que se rompeu algum tempo depois. Sua busca em análise foi a de reencontrar um ambiente que pudesse se interessar por ela tal como precisava ser, ambiente este que sobrevivesse à sua existência mesmo quando da "agressividade" incompassiva, de suas recusas e afastamentos, tal como Tita precisava que fosse.

Penso ser importante fazer aqui uma breve consideração em relação ao diagnóstico que fiz da paciente, o de depressão. Apesar de haver, por vezes, vivências que se aproximavam de dissociações e defesas que envolviam despersonalização, necessidade de afastamento para seu mundo subjetivo, havia em Tita a condição de 
nomeação de suas necessidades. Ainda que não pudesse evitar as angústias daí originadas, conseguia olhar para si mesma e dizer: "Eu preciso me afastar, eu preciso me reaproximar". Havia um ego integrado acompanhando suas experiências, identificadas como próprias. Entrar e sair desses estados de angústia era uma possibilidade (Winnicott, 1965, p. 107-8).

Recentemente, Tita trouxe-me um sonho e, de forma muito emocionada, encontrou seu significado. O sonho aconteceu depois de Tita dizer ao marido que não aguentava mais tanta intromissão em seu trabalho, que aquilo a sufocava. Depois dessa conversa, a qual teve, felizmente, um saldo positivo, a paciente sonhou que estava em um ateliê, observando cada detalhe e sentindo-se muito emocionada por estar ali. Percebeu que aquele era um lugar muito íntimo. De repente, viu-se com dois gatinhos no colo, um branco, gordo e muito saudável e outro preto e mirrado, ao qual, em suas palavras, "faltava um sopro de vida". Sentiu que deveria cuidar deste gatinho e voltou para trancar o ateliê, porém percebeu que lá dentro havia uma mulher desconhecida. Pensou, então, que não precisava trancar a porta, apenas encostá-la.

Nas associações que fez, disse: “[...] é disso que tenho saudade, de estar comigo, e isso nada tem a ver com sofrer ou estar triste, nem tem nada a ver com não querer ou não poder estar com os outros. Eu só preciso estar às vezes comigo mesma. Mas, se para estar comigo mesma eu precisar perder a outra pessoa, tudo perde o sentido".

Tita não busca a ausência de sofrimento, a solução de conflitos, a compreensão intelectualizada de suas experiências; ela busca, às vezes desesperadamente, ser ela mesma, vivamente, encontrando seus próprios significados para suas experiências. Talvez, por ser artista, pode trazer para a análise de forma viva o que, na verdade, está contido em todas as análises e no próprio processo de viver. Algo que passa pela possibilidade do encontro consigo mesma na presença de um outro que acompanha vivamente esse percurso, porém sem invadi-lo, tornando-o fecundo para ambas as partes envolvidas.

$\mathrm{Na}$ última sessão realizada com Tita antes da conclusão deste texto, ficou claro o que aqui exponho: Winnicott entende a transferência como regressão à dependência e estende esse entendimento para todo o espectro diagnóstico, sendo este o suporte essencial para o resgate do amadurecimento. Na sessão, contou como vinha se sentido diferente. Disse que não se sentia mais colada nas pessoas, como costumava acontecer. É tudo muito mais simples, tudo muito mais fácil, mas tem algo estranho, sem 
intensidade. Ou seja, é simples, é fácil, mas não tem nada de intenso. Deu alguns exemplos com um mesmo conteúdo de base e disse como estava sendo importante se fazer valer. Em uma das situações que relatou, sua mãe ligou para ela e, como sempre, falou muito das irmãs. Em um dado momento, Tita interrompeu o telefonema, com calma e educação, porque precisava trabalhar. Concluiu dizendo que, embora fosse uma atitude simples, não era capaz de dizer não, de dizer que não poderia e não queria mais escutar a mãe. "Eu tenho podido me fazer valer", concluiu. Usei essa frase para dizer-lhe que talvez essa fosse justamente a diferença que vinha sentindo: poder se fazer valer. Tita concordou, mas acrescentou que achava ainda mais importante a experiência do deslocamento. Relatou que estava conseguindo ouvir mais críticas e acatá-las ou rejeitá-las, segundo sua real pertinência.

Um exemplo disso, foi quando o pai de uma criança solicitou uma reunião, dizendo que seu filho precisava de um trabalho mais diretivo e centrado na técnica. Tita acatou o pedido, encontrando outra turma para o menino. Outro dia, uma voluntária, amiga da paciente que participava de uma das atividades do ateliê, chegou muito afetada por algo que lhe aconteceu e passou a agredir Tita; esta pode, então, não só não se colar à amiga, mas mostrar que estava sendo alvo de agressões as quais não guardavam relação com a sua pessoa. Descolar-se da crítica, sabendo que isso não a ameaçava, mas que se tratava apenas da necessidade do outro, era o mais importante. Ressalto à Tita que ela e o outro poderiam continuar existindo e se relacionando, ao que ela acatou. Passou, em seguida, a relatar outra experiência na qual se sentiu ela mesma, mas que envolveu algo muito intenso e que não sabia como relacionar com tudo o que estava vivenciando.

Contou-me a respeito de um menino que estava com ela em um dos ateliês mais importantes da instituição e no qual mais conseguiu se aprofundar. O garoto, que à época contava com nove anos de idade e hoje está com 12, chamou a atenção dela pela maneira como usava o próprio corpo. Tita descreveu, com brilho nos olhos, a beleza plástica daquele corpo em movimento, dizendo que a mesma estava na forma livre, precisa e ágil com que se deslocava pelo espaço. O menino ocupava os espaços como se fossem totalmente seus, com muitos saltos, cambalhotas e piruetas. Disse que não era somente ela que se encantava com o garoto, suas colegas e as outras crianças também. Em uma dada semana, a mãe do menino lhe disse que, depois de muito tempo na fila de espera, havia conseguido vaga em um programa de atendimento para crianças e adolescentes como complemento ao período escolar. Por conta disso, o 
garoto não frequentaria mais o ateliê de arte. Tita e o menino ficaram muito tristes com a notícia. Essa reciprocidade por parte da criança a deixou bastante emocionada. Depois de contar o acontecido, permaneceu em silêncio, chorando. Fez uma longa pausa e, então, repetiu que não entendia. Assinalo que Tita trouxe uma relação que condensava muitas das suas buscas na vida: o trabalho com o garoto, que já se estendia por três ou quatro anos, era uma experiência que perdurava no tempo, algo nunca antes alcançado. Era um contato com alguém que tinha uma beleza e uma liberdade de estar no mundo que a encantavam e que desejava para si mesma há muito tempo. Uma experiência que floresceu através de um olhar interessado, acontecendo de forma recíproca. A paciente, muito emocionada, disse que sabia como a vaga era importante para o menino e que, apesar da tristeza, ela precisava deixar que ele fosse embora. E, assim, a sessão terminou.

$\mathrm{Na}$ contramão das experiências de descolamento, que Tita tem podido experimentar cada vez mais, esta última é da ordem da fusão, como aquela de ver uma casa que a encantava e fundir-se a ela, lá ficando e perdendo-se de si. A experiência com esse menino, apesar de fusionada, introduz algo novo. Sem precisar se descolar da experiência, porque a mantém fortemente dentro de si, Tita pode, ainda que tristemente, considerar a realidade que impõe o afastamento.

Concluindo: as regressões são pedidos de ajuda, que exigem do analista a identificação do momento de origem do sintoma, seu diagnóstico e, seja ele qual for, a realização dos manejos adequados a essa fase, a fim de que o paciente possa, regredindo ao ponto de origem de seu sofrimento, resgatar seu verdadeiro si mesmo e seguir seu processo de integração em uma relação viva e real para ambos os lados.

\section{Referências bibliográficas}

Winnicott, D.W. [1962/ 1983]. Os objetivos do tratamento psicanalítico. In: Winnicott, D.W. O Ambiente e os Processos de maturação. Porto Alegre: Artes Médicas, 1983.

Winnicott, D. W. [1965/1994]. O valor da consulta terapêutica. In: Winnicott, C. Explorações Psicanalíticas: D. W. Winnicott. Porto Alegre: Artes Médicas Sul,1994.

Winnicott, D. W. [1965/1994]. O Conceito de Trauma em Relação ao Desenvolvimento do Indivíduo dentro da Família. In: Winnicott, C. Explorações psicanalíticas: D.W. Winnicott. Porto Alegre: Artes Médicas Sul, 1994. 
Winnicott, D.W. [1967/1975]. O papel do espelho da mãe e da família no desenvolvimento infantil. In: Winnicott, D.W. O Brincar e a Realidade. Rio de Janeiro: Imago Editora, 1975.

Winnicott, D. W. [1968/1999]. Sum, eu sou. In: Winnicott, D. W. Tudo Começa em Casa. São Paulo: Martins Fontes, 1999.

Winnicott, D. W. [1968/1975]. Inter-relacionar-se independentemente do impulso instintual e em função de identificações cruzadas. In: Winnicott, D.W. O Brincar e a Realidade. Rio de Janeiro: Imago Editora, 1975. 